\title{
Prevalence and Characterization of Cephalosporin Resistance in Nonpathogenic Escherichia coli from Food-Producing Animals Slaughtered in Poland
}

\author{
Wasyl, Dariusz; Hasman, Henrik; Cavaco, Lina; Aarestrup, Frank Møller
}

Published in:

Microbial Drug Resistance

Link to article, DOI:

$10.1089 / \mathrm{mdr} .2011 .0033$

Publication date:

2012

Document Version

Publisher's PDF, also known as Version of record

Link back to DTU Orbit

Citation (APA):

Wasyl, D., Hasman, H., Cavaco, L., \& Aarestrup, F. M. (2012). Prevalence and Characterization of Cephalosporin Resistance in Nonpathogenic Escherichia coli from Food-Producing Animals Slaughtered in Poland. Microbial Drug Resistance, 18(1), 79-82. https://doi.org/10.1089/mdr.2011.0033

\section{General rights}

Copyright and moral rights for the publications made accessible in the public portal are retained by the authors and/or other copyright owners and it is a condition of accessing publications that users recognise and abide by the legal requirements associated with these rights.

- Users may download and print one copy of any publication from the public portal for the purpose of private study or research.

- You may not further distribute the material or use it for any profit-making activity or commercial gain

- You may freely distribute the URL identifying the publication in the public portal 


\title{
Prevalence and Characterization of Cephalosporin Resistance in Nonpathogenic Escherichia coli from Food-Producing Animals Slaughtered in Poland
}

\author{
Dariusz Wasyl, ${ }^{1}$ Henrik Hasman, ${ }^{2}$ Lina M. Cavaco, ${ }^{2}$ and Frank M. Aarestrup ${ }^{2}$
}

The prevalence of Escherichia coli with putative extended-spectrum cephalosporin resistance was assessed in cattle, pigs, broilers, layers, and turkey slaughtered in Poland. The occurrence of random E. coli isolates recovered from MacConkey agar plates with non-wild-type minimal inhibitory concentrations for cefotaxime and ceftazidime reached $0.6 \%$ in layers, $2.3 \%$ in turkey, and $4.7 \%$ in broilers, whereas all cattle and pigs isolates fell into the wild-type subpopulation. The use of MacConkey agar supplemented with cefotaxime $(2 \mathrm{mg} / \mathrm{L})$ increased the recovery of resistant strains up to $33.3 \%$ of samples from pigs, $42.3 \%$ from layers, $48.0 \%$ from turkey, and $54.5 \%$ from broilers. Still, no cephalosporin-resistant E. coli was found in cattle. E-test identified extendedspectrum beta-lactamase (ESBL) and ampC-type resistance phenotypes in 15 and 33 strains, respectively. Molecular characterization identified CTX-M-1 gene in 13 ESBL strains, 5 of which possessed also TEM-1b. One strain harbored SHV-12 gene. CMY-2 was found in all of 20 tested ampC-type cephalosporinase-positive strains either alone $(n=14)$ or in combination with mutations in ampC promoter region $(n=6)$. CTX-M-1 and CMY-2 genes were noted also in five strains from laying hens and broilers originated from Belgium and Germany. Nosocomial infections in Poland are caused by E. coli carrying other determinants than those found in our study. Thus, our results indicate that animals colonized with cephalosporin-resistant strains might not be the major source of human infections in Poland. However, the contribution to community-acquired infections by spread of resistant clones or resistance genes may not be excluded.

\section{Introduction}

C EPHALOSPORIN-RESISTANT bacteria are frequently found in nosocomial and community-acquired infections. The contribution of food of animal origin and direct human to animal contact remains unclear, but several studies indicated food animals, pets, and wildlife as a reservoir of cephalosporinresistant bacteria. ${ }^{3,4,9,12,13}$ Numerous enzymes are associated with extended-spectrum cephalosporin (ESC) resistance including extended-spectrum beta-lactamases (ESBL), metallo-betalactamases (MBL), and ampC-type cephalosporinases and can be differentiated with phenotypic tests. ${ }^{16}$

The study aimed at assessing of the prevalence of ESC resistance and characterization of resistance mechanisms in Escherichia coli isolated from healthy food-producing animals slaughtered in Poland.

\section{Materials and Methods}

\section{Sampling and bacteriological examinations}

Rectal/cloacal swabs $(n=880)$ were randomly collected in 2009 during slaughter from cattle, pigs, broilers, turkey, and layers (Fig. 1). In routine antimicrobial resistance monitoring (ARM), the swabs were directly streaked onto McConkey agar. Additionally, 129 of the samples were simultaneously screened on MacConkey agar supplemented with cefotaxime ( $2 \mathrm{mg} / \mathrm{L})$ as described elsewhere. ${ }^{16}$ Colonies showing typical E. coli morphology were confirmed in ONPG and indol tube tests.

\section{Antimicrobial susceptibility testing}

Minimum inhibitory concentrations (MICs) were determined using customized Sensititer plates (Trek Diagnostic Systems) and interpreted according epidemiological cutoff values (http://eucast.org) to split bacterial population into wild-type (WT) and non-wild-type (NWT) strains. The latter group was considered to contain a resistance mechanism against the given antimicrobial, thus showing microbiological resistance. Isolates showing NWT MICs to ampicillin (NWT $>8 \mathrm{mg} / \mathrm{L}$ ), ceftazidime (NWT $>0.25 \mathrm{mg} / \mathrm{L}$ ), and cefotaxime (NWT $>0.5 \mathrm{mg} / \mathrm{L}$ ) were screened with E-tests (bioMerieux) to confirm possible ESC and differentiate between ESBL, MBL, and ampC-type phenotypes based on the synergy observed between, respectively, cefotaxime and

\footnotetext{
${ }^{1}$ Department of Microbiology, National Veterinary Research Institute, Pulawy, Poland.

${ }^{2}$ Department of Microbiology and Risk Assessment, National Food Institute, Technical University of Denmark, Lyngby, Denmark.
} 
- ARM, $\mathrm{N}=880^{*} \quad$ ESC selective screening $(\mathrm{N}=129)$

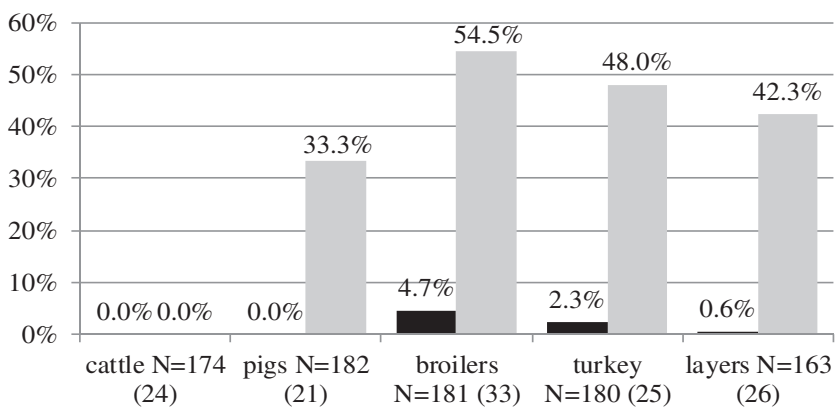

FIG. 1. ESC prevalence in Escherichia coli isolated from food animals (digits in brackets stands for number of samples tested with screening method). *Because of random sampling, 2 samples were collected from imported broilers (SK), and 32 laying flocks originated from Belgium $(n=5)$, Czech Republic $(n=4)$, Germany $(n=10)$, Lithuania $(n=1)$, The Netherlands $(n=4)$, and Slovak Republic. ESC, extendedspectrum cephalosporin.

clavulanic acid, imipenem and EDTA, and cefotetan and cloxacillin. ${ }^{16}$

\section{Cephalosporin-resistant strains}

A single ESC-resistant strain from each sample was selected for molecular characterization of resistance mechanisms as previously described. ${ }^{7}$ Fifteen ESBL-suspected strains were tested by PCR for SHV, TEM, CTX-M-1 group, CTX-M-2 group, and CTX-M-9 group genes. Twenty of 33 isolates showing ampC phenotype were screened for CMY-1 and CMY-2 genes and the ampC promoter was amplified in 14 of these. Sequencing of PCR amplicons was done at Macrogen Corporation and Vector NTI Advance 11 software was used for sequence analysis.

\section{Results}

The prevalence of E. coli with NWT MICs for both cephalosporins tested varied between the isolation sources (Fig.
1). Routine monitoring identified 13 ESC-positive samples: three ESBL producers were found in turkeys and ampC phenotype was noted in broilers $(n=8)$ and single turkey and layers isolates. Another 12 ESBL producers and 23 ampCtype resistances were noted in selective screening of pigs (4 and 3 , respectively), layers (5 and 5), turkeys (2 and 6), and broilers (1 and 9). Resistance mechanism identification was in congruence with phenotypic identification (Table 1). CTXM-1 beta-lactamase $(n=13)$ and CMY-2 cephalosporinase $(n=20)$ were most frequently found in some strains accompanied with TEM-1b $(n=5)$ and ampC mutations $(n=6)$. A single SHV-12-producing strain was noted and the genetic background of resistance was not identified in another single strain. Interestingly, three CTX-M1 and two CMY-2 producers were found in samples from imported animals. None of the strains was positive for CTX-M-2 group, CTX-M-9 group, or CMY-1.

\section{Discussion}

Our study showed that poultry and pigs might be a reservoir of third-generation cephalosporin-resistant E. coli. Compared with humans mostly colonized with a defined resistant strain, 6,11 enteric bacteria in healthy animals constitute of mixed commensal population including a fraction of ESC strains. ${ }^{1,8-10}$ Previous studies have demonstrated that selective screening is needed for enhanced recovery of such isolates. ${ }^{3,16}$ Cephalosporin usage may select for higher prevalence of strains with NWT MICs and explain the observed differences in different animal reservoirs. $3,10,13$

Although we cannot distinctly conclude on the real prevalence of ESC in E. coli, the resistance mechanisms were identified. Like few other studies, ESBL-positive strains were less frequent compared with ampC-type cephalosporinase producers. ${ }^{5,13}$ In contrast with other studies, $5,8,10$ no ESC genes were found in cattle isolates. Surprisingly, a low diversity of resistance genes was found, although the strains were obtained over several months from various animal species at random, countrywide settings. Recent ESC studies have revealed a variety of genes present in animal gut flora and the ones found in our study have been already reported in wild, food-producing and companion animals, both in commensal E. coli and clinical cases. ${ }^{1-5,9,10,13}$ They were often

Table 1. Resistance Mechanisms by Source of Escherichia coli Isolation

\begin{tabular}{|c|c|c|c|c|c|c|}
\hline \multirow[b]{2}{*}{ Phenotype } & \multirow[b]{2}{*}{ Resistance mechanism } & \multicolumn{5}{|c|}{ No. of strains } \\
\hline & & Pigs & Layers & Broilers & Turkeys & Total \\
\hline \multirow[t]{4}{*}{$\operatorname{ESBL}(n=15)$} & CTX-M-1 & 2 & $3^{\mathrm{a}}$ & & 3 & 8 \\
\hline & CTX-M-1+TEM-1b & 1 & 2 & 1 & 1 & 5 \\
\hline & SHV-12 & & & & 1 & 1 \\
\hline & Not identified & 1 & & & & 1 \\
\hline \multirow[t]{5}{*}{$\operatorname{ampC}(n=33)$} & CMY-2 & & $4^{\mathrm{b}}$ & $10^{\mathrm{b}}$ & & 14 \\
\hline & CMY-2+ampC overexpression: & & & & & \\
\hline & $\mathrm{C}-88 \mathrm{~T}+\mathrm{A}-82 \mathrm{G}+\mathrm{G}-18 \mathrm{~A}+\mathrm{C}-1 \mathrm{~T}+\mathrm{C} 58 \mathrm{~T}$ & 1 & & 2 & 1 & 4 \\
\hline & $\mathrm{C}-73 \mathrm{~T}+\mathrm{G}-28 \mathrm{~A}+\mathrm{C} 58 \mathrm{~T}$ & & & 2 & & 2 \\
\hline & Not tested & 2 & 2 & 3 & 6 & 13 \\
\hline
\end{tabular}

\footnotetext{
astrains isolated from flocks imported from Belgium.

${ }^{\mathrm{b}}$ Strain isolated from flocks imported from Germany.

ESBL, extended-spectrum beta-lactamase.
} 
found in associations ${ }^{1,12}$ including promoter mutations resulting in hyperproduction of chromosomal ampC betalactamases. 3,12

This is the first study on the genetic background of ESC in commensal E. coli isolated from animals slaughtered in Poland, although numerous reports are available from other countries. ${ }^{1-5,7,9,13}$ Unsurprisingly, two predominant resistance mechanisms were also found in strains traced back to flocks originating from three other countries.

Animals via contaminated food or direct contact might contribute to human colonization with resistant bacteria. For example, CTX-M-1 beta-lactamase was previously reported in beef and poultry meat in Tunisia and chicken breast in the United Kingdom. ${ }^{8,15}$ The prevalence of TEM- 52 in animals was correlated to human infections in Portugal. ${ }^{2,3}$ Because of plasmidic location of most of ESC resistance genes, numerous studies relate animal-to-man spread of ESC rather to plasmid transfer than clonal spread of bacteria., $1,3,4,9-11$ Having the above in mind as well as a variety of genes found in healthy humans, ${ }^{10,14}$ one may assume that transmission of ESC might occur within the food chain. This scenario may not be confirmed by our findings, supported with public health data on high prevalence of CTX-M-15 and M-3 nosocomial infections. ${ }^{6}$ Similar discrepancies between ESC resistance genes found in man and food have been reported by Warren et al. ${ }^{15}$

Our report adds new country to the worldwide landscape of ESC occurrence in indicator E. coli isolated from animals. The findings do not support food animals colonized with resistant strains as a major source of human infections, although they might contribute to international spread of resistance mechanisms and compromise animal welfare. At some point it might also challenge human health precisely with respect to community-acquired infections with ESC bacteria. This issue could be verified by simultaneous survey of animals, foods, and nondiseased individuals representative of the community.

\section{Acknowledgments}

The work at NVRI was supported by governmental funding of "Protection of animal and human health" (Ministry of Council Resolution No. 244/2008). Part of the research was performed at the EURL-AR at the National Food Institute in Copenhagen. The authors thank Lisbeth Andersen, Danuta Wnuk, and Anna Lalak for excellent technical assistance.

\section{Disclosure Statement}

No competing interests exist.

\section{References}

1. Bortolaia, V., L. Guardabassi, M. Trevisani, M. Bisgaard, L. Venturi, and A.M. Bojesen. 2010. High diversity of extended-spectrum beta-lactamases in Escherichia coli isolates from Italian broiler flocks. Antimicrob. Agents Chemother. 54:1623-1626.

2. Costa, D., P. Poeta, L. Brinas, Y. Saenz, J. Rodrigues, and C. Torres. 2004. Detection of CTX-M-1 and TEM-52 betalactamases in Escherichia coli strains from healthy pets in Portugal. J. Antimicrob. Chemother. 54:960-961.
3. Costa, D., L. Vinue, P. Poeta, A.C. Coelho, M. Matos, Y. Saenz, S. Somalo, M. Zarazaga, J. Rodrigues, and C. Torres. 2009. Prevalence of extended-spectrum betalactamase-producing Escherichia coli isolates in faecal samples of broilers. Vet. Microbiol. 138:339-344.

4. Dierikx, C., A. van Essen-Zandbergen, K. Veldman, H. Smith, and D. Mevius. 2010. Increased detection of extended spectrum beta-lactamase producing Salmonella enterica and Escherichia coli isolates from poultry. Vet. Microbiol. 145:273-278.

5. Doi, Y., D.L. Paterson, P. Egea, A. Pascual, L. LopezCerero, M.D. Navarro, J.M. Adams-Haduch, Z.A. Qureshi, H.E. Sidjabat, and J. Rodriguez-Bano. 2010. Extendedspectrum and CMY-type beta-lactamase-producing Escherichia coli in clinical samples and retail meat from Pittsburgh, USA and Seville, Spain. Clin. Microbiol. Infect. 16: 33-38.

6. Empel, J., A. Baraniak, E. Literacka, A. Mrowka, J. Fiett, E. Sadowy, W. Hryniewicz, and M. Gniadkowski. 2008. Molecular survey of beta-lactamases conferring resistance to newer beta-lactams in Enterobacteriaceae isolates from Polish hospitals. Antimicrob. Agents Chemother. 52:24492454.

7. Hasman, H., D. Mevius, K. Veldman, I. Olesen, and F.M. Aarestrup. 2005. Beta-lactamases among extended-spectrum beta-lactamase (ESBL)-resistant Salmonella from poultry, poultry products and human patients in the Netherlands. I. Antimicrob. Chemother. 56:115-121.

8. Jouini, A., L. Vinue, K.B. Slama, Y. Saenz, N. Klibi, S. Hammami, A. Boudabous, and C. Torres. 2007. Characterization of CTX-M and SHV extended-spectrum betalactamases and associated resistance genes in Escherichia coli strains of food samples in Tunisia. J. Antimicrob. Chemother. 60:1137-1141.

9. Meunier, D., E. Jouy, C. Lazizzera, M. Kobisch, and J.Y. Madec. 2006. CTX-M-1- and CTX-M-15-type beta-lactamases in clinical Escherichia coli isolates recovered from foodproducing animals in France. Int. J. Antimicrob. Agents 28:402-407.

10. Moodley, A., and L. Guardabassi. 2009. Transmission of IncN plasmids carrying blaCTX-M-1 between commensal Escherichia coli in pigs and farm workers. Antimicrob. Agents Chemother. 53:1709-1711.

11. Peirano, G., and J.D. Pitout. 2010. Molecular epidemiology of Escherichia coli producing CTX-M beta-lactamases: the worldwide emergence of clone ST131 O25:H4. Int. J. Antimicrob. Agents 35:316-321.

12. Poeta, P., H. Radhouani, L. Pinto, A. Martinho, V. Rego, R. Rodrigues, A. Goncalves, J. Rodrigues, V. Estepa, C. Torres, and others. 2009. Wild boars as reservoirs of extended-spectrum beta-lactamase (ESBL) producing Escherichia coli of different phylogenetic groups. I. Basic Microbiol. 49:584-588.

13. Smet, A., A. Martel, D. Persoons, J. Dewulf, M. Heyndrickx, B. Catry, L. Herman, F. Haesebrouck, and P. Butaye. 2008. Diversity of extended-spectrum beta-lactamases and class $C$ beta-lactamases among cloacal Escherichia coli isolates in Belgian broiler farms. Antimicrob. Agents Chemother. 52:1238-1243.

14. Vinue, L., Y. Saenz, S. Martinez, S. Somalo, M.A. Moreno, C. Torres, and M. Zarazaga. 2009. Prevalence and diversity of extended-spectrum beta-lactamases in faecal Escherichia coli isolates from healthy humans in Spain. Clin. Microbiol. Infect. 15:954-957. 
15. Warren, R.E., V.M. Ensor, P. O'Neill, V. Butler, J. Taylor, K. Nye, M. Harvey, D.M. Livermore, N. Woodford, and P.M. Hawkey. 2008. Imported chicken meat as a potential source of quinolone-resistant Escherichia coli producing extended-spectrum beta-lactamases in the UK. I. Antimicrob. Chemother. 61:504-508.

16. Wasyl, D., A. Hoszowski, M. Zając, and M. Skarżyńska. 2010. Simple and efficient screening method for detection of cephalosporin resistant Escherichia coli. Bull. Vet. Inst. Pulawy 54: 147-151.
Address correspondence to:

Dariusz Wasyl, D.V.M., Ph.D.

Department of Microbiology National Veterinary Research Institute

Partyzantow 57 24-100 Pulawy

Poland

E-mail: wasyl@piwet.pulawy.pl 